\title{
Reality and Contemporary Economic Classification of Expenditures of Public Institutions in Romania
}

\author{
Carolina Daniela Soroceanu, “Alexandru Ioan Cuza” University Iaşi, Romania
}

\begin{abstract}
In our daily existence, troubled and changing, economy occupies a large space. Increasingly, more economic concepts such as public budget and public expenditures enter within our daily language. Increasingly, we are assailed with data information about the sustainability of expenditure, about how and when budget allows us to make certain expenditures. Thus, an insight into the functional mechanism and a public institutional budget is always a topical issue.

About the budget, as a financial and management tool of a public, we can not discuss without reference to economic classifiers public spending. Budget public institution acquires through economic classification of expenditure substance and reality.
\end{abstract}

\section{Keywords}

budget, public institutions, economic classification,public expenditures

JEL Code: H60, H61, H83

Extending the scope of economic phenomena, the complexity and diversity of the expenditure requires rendering financial data tools, in order to facilitate access and processing information. From this perspective, statistics, and especially the financial one, there can be limited to a quantitative description of phenomena but had to provide tools for analysis and interpretation. Among them, economic classifiers public spending has grown with the company whose financial information has played. Classifieds economic costs presented over time, or physical terms or in combination with the real monetary terms, reaching far, the form we know, monetary. One can say that each period of development have complied with certain classification criteria that reflected what was important and of interest to the community. For this reason the classification criteria experienced different forms, from natural classification, where the clustering criterion is chosen objectively as intrinsic features of the units surveyed, to artificial classification, which is specific the choice of conventional or subjective criteria starting from several distinctive features of the entities studied. The two classification methods are not excluded, at present economic Classifieds and public expenditure are in connection. Subjectivity and conventionalism are particularly deep as the default budget and economic Classifieds is a working tool for the "laity and experts" after the words of Friedman.

Whatever the period we refer to, economic Classifieds of public spending follow-up to meet economic realities.

Classifications grouped a significant number of information in a systematic and standardized way.

Preparation of a classification means creating a comprehensive and structured set of categories well described and mutually exclusive, most often through a hierarchical structure which is reflected by alphabetical or numerical codes assigned to them.

The current economic classifiers have a horizontal structure in parts that are then developed analytical vertical in titles, articles and paragraphs. Parties are sub-grouping for general 
purpose expenditure policy, like current expenditure, capital expenditure and financial operations. Titles group expenditures which show common purposes in the party for the staff, supplies and services, interest, grants, reserve funds, transfers between units of government, other transfers, social assistance, other expenses, non-financial assets, financial assets, loans, repayments of loans and finally reserves, surplus / deficit.

Titles are detailed in articles and these turned into paragraphs. All these subdivisions individualize real destinations of public spending.

When we refer to the completeness, uniqueness and homogeneity of the economic classification of expenditure, things are more complex. There are articles and redundant lines that confuse and are subjected to a large extent to arbitrary and interpretation of the employing expenses.

The problem is not only invalidity of statistical principles but also to the extent that statistical statements are based on data collected in these articles reflect or not the true economic process.

For example we will treat a few articles and paragraphs of economic classification of public institutions expenditures.

Budget item 20.01.06 "Spare Parts" is the new introduced in economic classification in 2005, because there already existed and exists the budget item 20. 02 "Current Repair". We make this observation in the context in which it is known that all the spare parts are acquired to carry out repairs to fixed assets and inventory objects.

On the other hand, keeping the current classification of budget item that refers to capital repairs finds no justification. This, especially in conditions of market economy where prices are variable and the appreciation of the value that encircle a repair to the inventory objects or fixed assets in the category of capital is difficult to realize. If before 1989 there was a classification which established thresholds at which discusses capital repairs, then at public institutions has not been developed such an overarching normative setting of this value.

This approach can be made for several items of the budget in condicions which both range of products and services that are necessary for carrying out public institutions and their benefits to beneficiaries - people diversified.

What is meant to be stressed is that, because of inertia of the past and the enthusiasm of the presnt some budget items were retained from the existing economic classifiers before the year 1989 in Romania and others were introduced by classification translating used in practice of other states.

Putting the principles and mechanisms, ideas and facts, ignoring Romanian institutional molds, taking applicable concepts with ten or even five years ago in practice and economic theory to say the burden of the past and desire accelerated progress can degenerate into mistakes.

Standard statistical classifications is a subset used to organize and present financial and economic statistics. When adopting or adapting a classification, norms are necessary for consistency procedures.

If economic classification applicable to the year 2006 methodological norms are still awaiting methodological clarification. For existent items was used the tutorial from 1995. Moreover, at the introduction of the current classification the legislative act contains a table of transposing the old positions in the new articles and budgetary paragraphs.But, even so, employment difficulties and mismatches of spending can be encountered in practice.

From another perspective, from the role fulfilled by the statistics in the economic life, classification can be built to support the implementation of regulatory policies of the state. These are also used to standardize the concepts of public services and to describe social and economic phenomena or social nature.

We refer here to recent legislation to reduce public spending.

It was specified in regulations in place that the reduction of twenty percent to apply the Title II, that Goods and services. 
Beyond fiscal theories on the role of state in conditions of crisis, we want to dwell on the following considerations.

As long as that legislation focused only on certain categories of expenditure there is a risk that, in the absence of clear financial rules to witness the growth of expenditure. It is the situation of inventory objects. It is known that a good falls in the category of inventory items if that has a value below the limit set by law for fixed assets, regardless of duration of use or duration of use less than one year. To meet the reduction of costs may exist, in practice the situation where there will no longer be purchased goods that make the subject to the budget item of inventory items but will be classified under fixed assets. Of course, we discuss in this situation either about the purchase of a landmark with superior technical features or of a undesirable situation, located at the limit of legality of artificial increase of the purchase price. Both versions are presented hypothetical, but still may appear more serious, can generalize the practice of public financial institutions. To remember that the investments article does not subject to reduction of expenses.

The same approach can be extended to the budgetary position of the current repairs. In this case, we could witness the fit of current repairs, under the category of those that are capital or even of investment category by increasing acquisition values.

We do not want the presentation of these considerations to speculate that it may reflect a negative image of the financial management of public institutions but only to emphasize the importance of quality work tools. We refer here to economic Classifieds expenditure of public institutions and mechanisms that fulfills a primary or secondary role.

Therefore, a reconsideration of budgetary articles and positions that make up is a laborious but necessary step.

These are just some of the considerations on the impact of economic classification of budget Romanian public institutions.

Always in the beating of subjective and objective waves of the researchers and practitioners, of specialists and "neophyte", economic classification of public institutions costs will be regularly reviewed, subject to approval and denial, also, to get the right balance between continuity and response to new challenges and the opportunity for public expenditure budget to be managed efficiently and effectively.

\section{References}

5. Constantin Jitaru - Accounts of government institutions, Didactic and Pedagogic Publishing House, Bucharest, 1996

6. Constantin Topciu - Budget Accounting, Didactic and Pedagogic Publishing House, Bucharest, 1970

7. Constantin Topciu - Evidence budget, Romanian Writing Publishing, Craiova, 1977.

8. Constantine Topciu - Budget and budgetary records, Didactic and Pedagogic Publishing House, 1981 Legal documents

44. Ministry of Finance - Plan accounts for state institutions and its implementing instructions, second edition of the revised and updated, approved by the Order number 324 of December 21, 1984.

45. MEF - Instructions on the organization and functioning of the treasuries of Public Finance, 1992

Ministry of Finance - MoF Order 1394/1995 Budget classification of income and expenditure of state and public institutions.

Ministry of Public Finance - OMFP 1954 / 2005

46. www.biblioteca-digitala.ase.ro

47. www.unibuc.ro/CLASSICA

48. www.mfinanțe.ro 